\title{
SÍNTESE DE UM COMPLEXO DE GLICINATO DE COBRE (II) MONOHIDRATADO
}

\section{ARTIGO ORIGINAL}

OLIVEIRA, Leandro José Dias Gonçalves de ${ }^{1}$

OLIVEIRA, Leandro José Dias Gonçalves de. Síntese de um complexo de glicinato de cobre (II) monohidratado. Revista Científica Multidisciplinar Núcleo do Conhecimento. Ano 04, Ed. 07, Vol. 10, pp. 87-96. Julho de 2019. ISSN: 2448-0959

\section{RESUMO}

Os compostos de coordenação são basicamente caracterizados por um íon de um metal do bloco $d$, denominado ácido de Lewis rodeado por ligantes denominados bases de Lewis, e geralmente seus sais apresentam coloração intensa quando em solução. O glicinato de cobre (II) monohidratado é um sólido de cor azul-esverdeada, e apresenta formas isoméricas cis/trans. O presente trabalho visa relatar o processo de síntese e caracterização a nível qualitativo desse complexo no laboratório químico da Escola Municipal Governador Israel Pinheiro, de João Monlevade, MG. Os resultados do experimento revelaram cristais de cor característica do composto pretendido e rendimento percentual favorável.

Palavras-chave: Síntese química, glicinato de cobre, complexo, composto de coordenação.

\section{INTRODUÇÃO}

As sínteses químicas nos permitem obter produtos mais complexos e de interesse para a sociedade partindo-se de substâncias mais simples. Grande parte dos avanços tecnológicos foram possíveis graças a esses estudos. Processos de síntese se fazem

\footnotetext{
${ }^{1}$ Químico (UNIUBE). Especialista em Ensino de Química (UCAM). Acadêmico do curso de Especialização em Educação em Ciências (UFMG).
} 
presentes nas indústrias químicas, farmacêuticas, no campo da biologia e biotecnologia, entre outros. Os processos de síntese química objetivam não somente criar novas substâncias, mas desenvolver métodos reacionais de maior viabilidade econômica.

Isenmann (2013) apud Oliveira et al (2018) diz que antes de pensar em planejamento de síntese, devemos procurar informações básicas, como entendimento dos mecanismos das reações, conhecimento das reações clássicas, noções de estequiometria, métodos de purificação e quais compostos estão prontamente disponíveis.

Dentre os milhares de compostos sintetizados pelo homem estão os complexos. $\mathrm{Na}$ definição de Russel (1994) um complexo é constituído por um átomo central, ou principal, circundado por e ligado a um ou mais ligantes, os quais podem ser átomos, íons ou moléculas. Atkins e Jones (2012) complementam, dizendo que os ligantes são orientados ao metal por ligações coordenadas.

É comum que haja formação de complexos com elementos dos blocos $d$ e $f$ com orbitais disponíveis para novos elétrons. O glicinato de cobre (II) - [Cu(gly)2], é um sal que possui diferentes rotas para ser sintetizado, e o método e reagentes influenciam quando se quer obter distintamente as formas cis e trans do composto. Para Shriver e Atkins (2003), complexos metálicos têm um importante papel na química inorgânica, em especial aqueles formados por metais do bloco $d$.

Figura 01 - Estruturas trans-bis-[Cu(gly $\left.)_{2}\right]$ e cis-bis-[Cu(gly $\left.)_{2}\right]$.
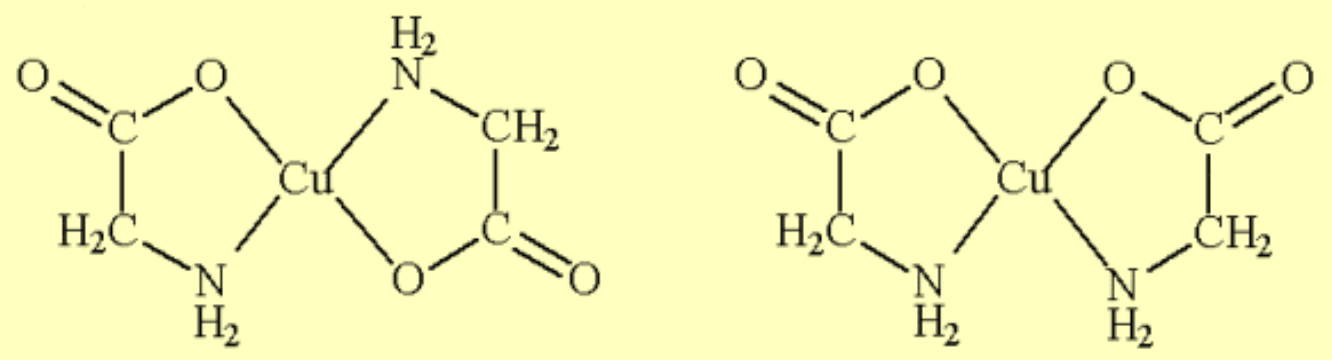

Fonte: Cotton S., Uppingham Scholl, Rutland, 2010. 
Os complexos metálicos são compostos interessantes, pois exibem muitas propriedades peculiares quanto a: estruturas, cores, propriedades ópticas e magnéticas, por exemplo. Outra característica que pode mencionar refere-se ao fato de formarem sais que não liberam seus íons em meio aquoso, mantendo sua integridade química. Os compostos de coordenação dividem-se em dois grupos: os sais duplos, aqueles que perdem sua identidade, e os complexos, que são aqueles que mantêm a identidade. (Hoehne e Dall'Oglio, 2013).

Este trabalho objetiva descrever o método utilizado na obtenção de um dos isômeros de glicinato de cobre (II) partindo-se do ácido aminoacético e do acetato de cobre (II) monohidratado, realizado no laboratório de uma escola técnica de João Monlevade, MG, e fazer uma análise qualitativa simples sobre o composto formado.

\section{MÉTODO}

Utilizando um béquer de $50 \mathrm{~mL}$ dissolveram-se 2,0 $\mathrm{g}$ de acetato de cobre (II) monohidratado em $25 \mathrm{~mL}$ de água deionizada aquecida, procedendo à posterior aquecimento progressivo utilizando o aparato montado com bico de Bunsen. Foram adicionados a essa solução $25 \mathrm{~mL}$ de etanol P.A., previamente aquecido. Continuouse a manter a mistura sob aquecimento. Em outro béquer, dissolveram-se $1,5 \mathrm{~g}$ de ácido aminoacético em $25 \mathrm{~mL}$ de água deionizada quente. Foram mantidos ambos os béqueres sob aquecimento até que atingissem $70^{\circ} \mathrm{C}$ (utilizou-se termômetro para acompanhar a temperatura). À mistura de acetato de cobre (II) monohidratado adicionou-se a solução de ácido aminoacético. A mistura foi deixada em repouso até que atingisse a temperatura ambiente. Em seguida imergiu-se o béquer em banhode-gelo. Decorridos alguns minutos, o conteúdo do béquer foi filtrado utilizando-se o papel filtro qualitativo de massa previamente determinada. Lavou-se o conteúdo do funil com etanol. Após a completa filtragem retirou-se o papel filtro do funil, que foi aberto sobre a bancada até completa evaporação do álcool. Mediu-se a massa do conteúdo sobre o papel filtro e calculou-se o rendimento da reação. 


\section{RESULTADOS E DISCUSSÕES}

Foram medidas as massas do ácido aminoacético e do acetato de cobre (II) monohidratado, cujos valores encontrados foram respectivamente 1,5009 g e 2,0036 g. Após, fez-se a medição da massa do papel filtro qualitativo, encontrando-se o valor de 1,1609 g. Observou-se imprecisão de medição de massa na quarta casa decimal para o ácido aminoacético e para o papel filtro qualitativo e na terceira e quarta casa decimais para o acetato de cobre (II) monohidratado.

O acetato de cobre é um sal de coloração azul-esverdeada enquanto o ácido aminoacético é ácido orgânico incolor. Durante a fase de aquecimento não houve alterações notáveis nos conteúdos dos béqueres, sendo que os mesmos apresentavam nitidamente as cores dos respectivos reagentes utilizados.

Figura 02 - Fase de aquecimento dos reagentes.

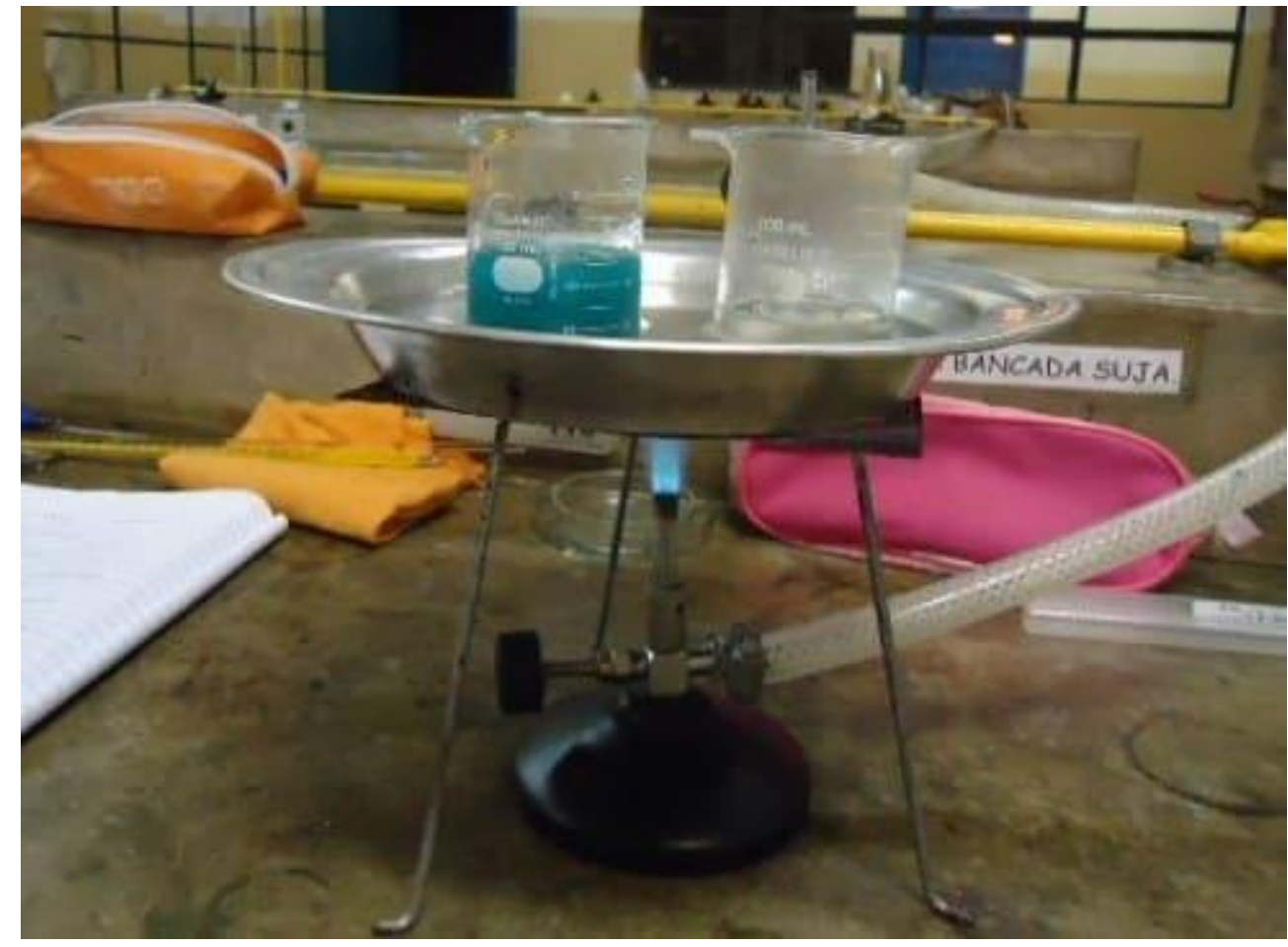

Fonte: $\mathrm{O}$ autor. 
A mudança notória ocorreu quando se colocou a solução de ácido aminoacético no béquer contendo a mistura de acetato de cobre (II) monohidratado e etanol. Revelouse uma coloração azul. $O$ béquer foi retirado do aparato de aquecimento e colocado sobre a bancada até que atingisse a temperatura ambiente.

Figura 03 - Mistura decorrente da mistura entre os reagentes.

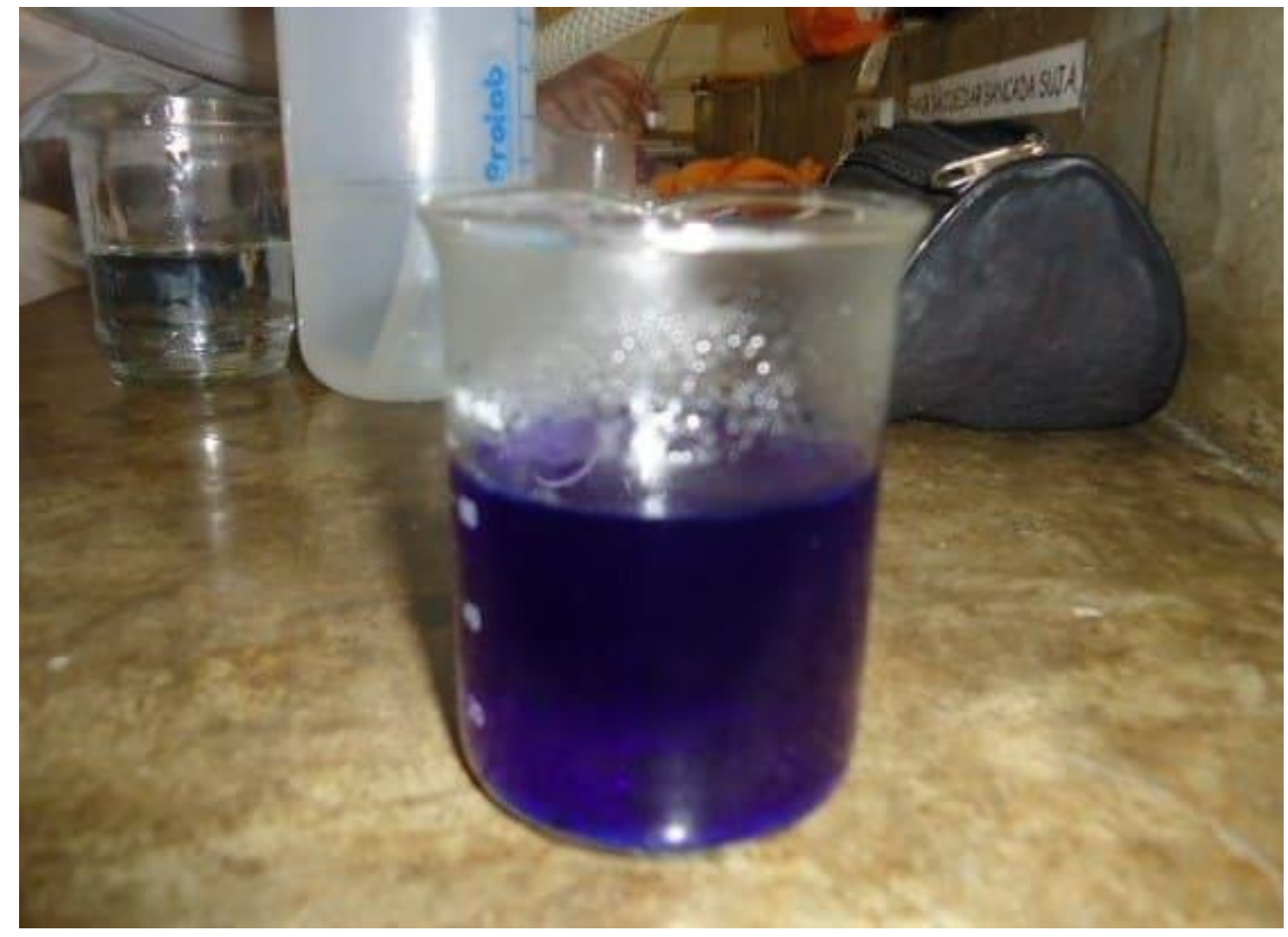

Fonte: $\mathrm{O}$ autor.

A coloração observada é devida ao íon de cobre $\mathrm{Cu}^{2+}$ hidratado, metal responsável pela formação de vários complexos de interesse científico, dentre eles, o glicinato de cobre (II) monohidratado, que despertou o interesse maior dos alunos ao revelar sua intensa coloração. Muitos elementos do bloco $d$ formam soluções com cores características em água (ATKINS e JONES, 2012). Outras características, tais como condutividade, cor, compostos com a mesma composição molecular, mas cor e momento de dipolo diferentes foram observados nesta nova classe de compostos (COELHO, 2010). 
A cor que uma substância exibe correspondente, portanto, à fração da luz visível que ela não absorve. A absorção de radiações ultravioletas abaixo de 400 não é detectada pelo olho humano, e percebemos as radiações infravermelhas como calor (SOUZA, s.d.).

$\mathrm{Na}$ química a variedade de cores encanta a todos e, de fato, mudança de cor é um indício de reação química. As cores são importantes pois podem revelar mais detalhes sobre um composto em análise. Tendo como base o glicinato de cobre (II) monohidratado, o sal revelou coloração característica do íon complexo. Segundo Atkins e Jones (2012), se o complexo é azul é porque ele está absorvendo a luz laranja (580-620 nm). Laranja e azul são cores complementares.

Figuras 04 - Círculo cromático.

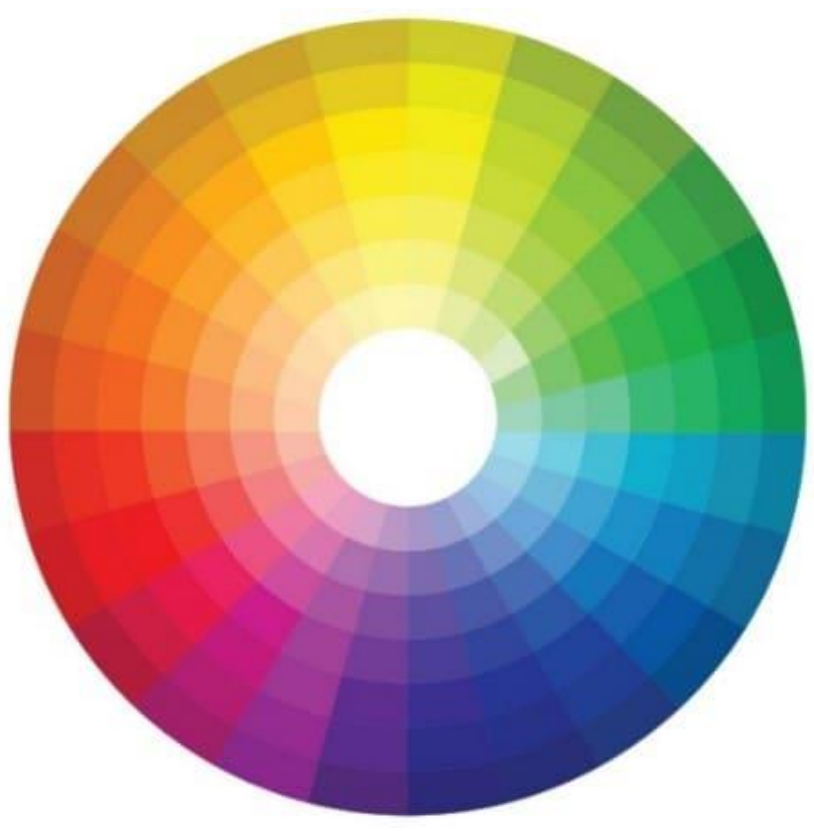

Fonte: Elgin, 2017.

Para que um composto tenha cor, ele deve absorver luz visível. Um composto absorverá radiação visível quando aquela radiação possuir a energia necessária para mover um elétron de seu estado de energia mais baixo (fundamental) para um estado excitado (BROWN, 2003). 
Depois que a mistura do béquer atingiu a temperatura ambiente, aferida com um termômetro, imergiu-se o béquer em banho-de-gelo. Cristais demasiado brilhantes de uma coloração azul, um pouco menos intensa, se mostraram maiores e mais definidos. Os cristais do sal demonstraram pouca solubilidade em meio aquoso quando submetidos a baixa temperatura.

Figuras 05/06 - Cristais de glicinato de cobre (II).
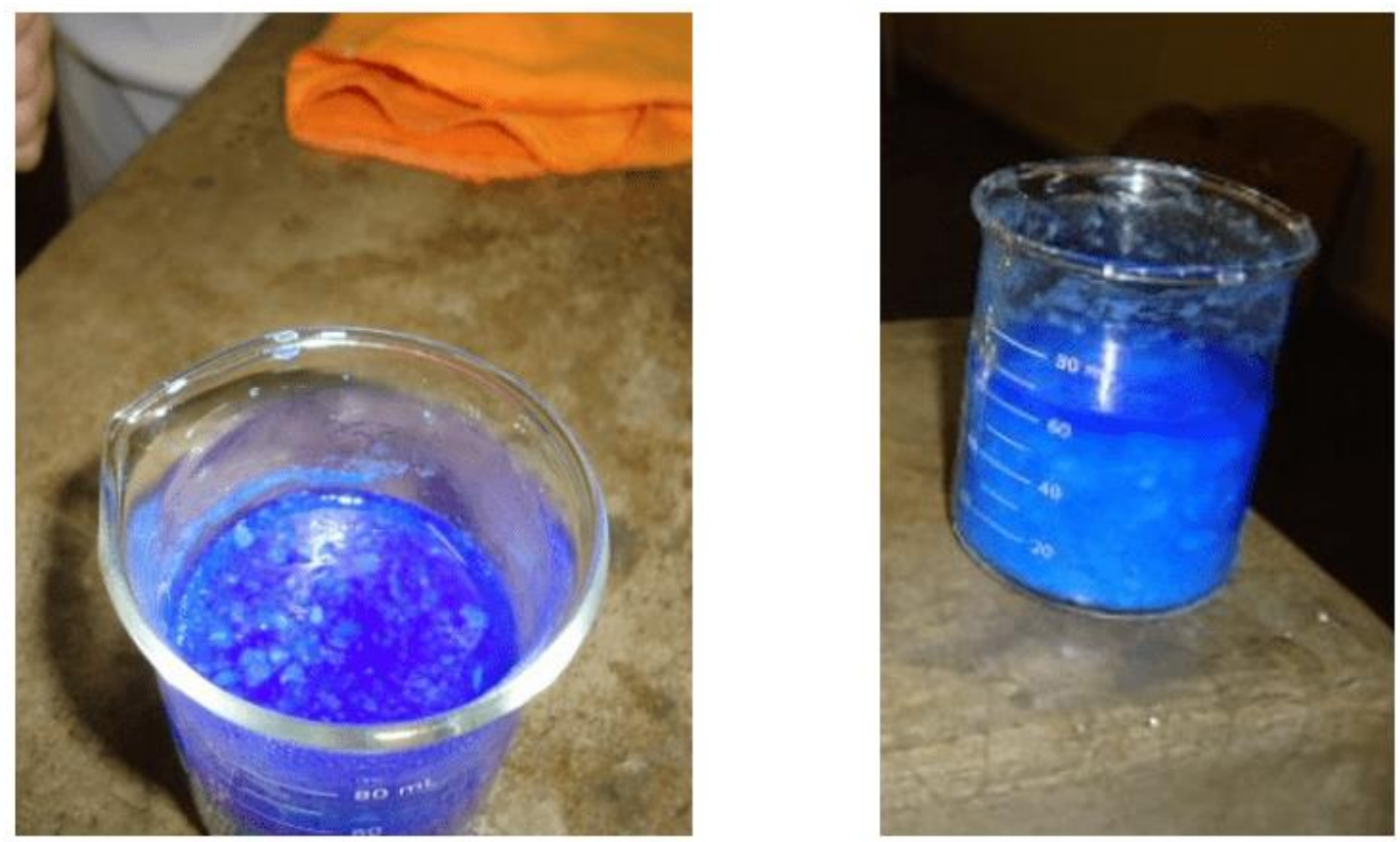

Fonte: $\mathrm{O}$ autor. 
Figura 07 - Aparato de filtração.

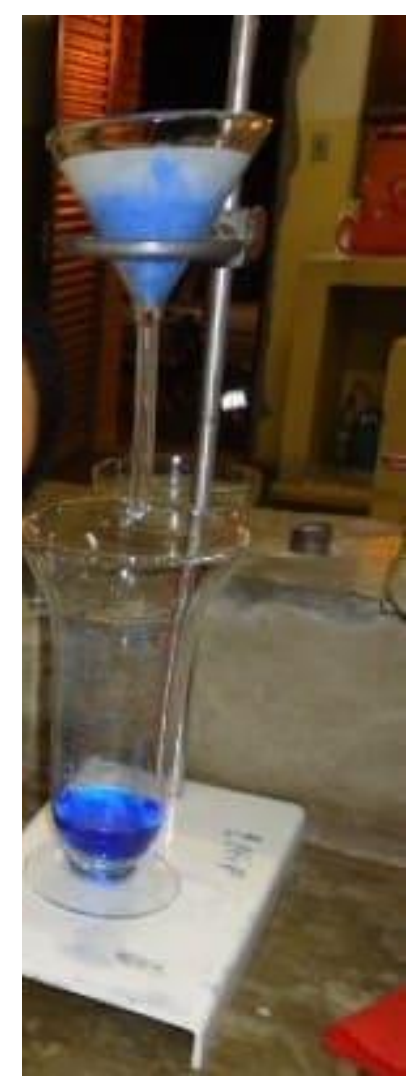

Fonte: $\mathrm{O}$ autor.

Após alguns minutos, montou-se 0 aparato de filtragem, com intuito de reter a parte sólida que foi se formando à medida que a temperatura foi reduzindo. À medida que o volume do filtrado aumentava no cálice, devido a lavagem contínua feita com etanol, podiam-se ver os cristais do glicinato de cobre (II), muito unidos, aparentemente macerados, de coloração azul intensa. A cor do complexo depende do metal, mas também dos ligantes, o que significa que mudanças nas substituições podem acarretar mudanças de cor. Finda a filtragem, o papel filtro foi retirado e aberto sobre a bancada, para que passasse sobre ele uma corrente de ar.

A reação que ocorreu para a formação do composto de coordenação é dada pela equação

$\mathrm{Cu}\left(\mathrm{CH}_{3} \mathrm{COO}\right)_{2}+2 \mathrm{NH}_{2} \mathrm{CH}_{2} \mathrm{COOH}+\mathrm{H}_{2} \mathrm{O}\left[\mathrm{Cu}\left(\mathrm{NH}_{2} \mathrm{CH}_{2} \mathrm{COO}\right)_{2}\right] . \mathrm{H}_{2} \mathrm{O}+2 \mathrm{CH}_{3} \mathrm{COOH}$ 
Após a completa evaporação do etanol que umedecia o papel filtro, sobraram apenas os cristais. A massa dos cristais com o papel filtro foi 2,9385 g. Portanto, a massa dos cristais isolados corresponde a $1,7776 \mathrm{~g}$.

Para o cálculo do rendimento da reação de síntese do glicinato de cobre fez-se necessário determinar as massas molares dos reagentes envolvidos, sendo

$\mathrm{Cu}\left(\mathrm{CH}_{3} \mathrm{COO}\right)_{2}=181,62982 \mathrm{~g} \cdot \mathrm{mol}^{-1}, \mathrm{NH}_{2} \mathrm{CH}_{2} \mathrm{COOH}=75,42662 \mathrm{~g} \cdot \mathrm{mol}^{-1} \mathrm{e}$

[Cu $\left.\left(\mathrm{NH}_{2} \mathrm{CH}_{2} \mathrm{COO}\right)_{2}\right] . \mathrm{H}_{2} \mathrm{O}=229,67450 \mathrm{~g} \cdot \mathrm{mol}^{-1}$. Os cálculos realizados seguem abaixo, utilizando-se todas as casas decimais com finalidade de deixar o resultado mais preciso:

$1 \mathrm{~mol} \mathrm{NH} \mathrm{CH}_{2} \mathrm{COOH}$ $75,42662 \mathrm{~g}$

$2 \mathrm{~mol} \mathrm{NH}_{2} \mathrm{CH}_{2} \mathrm{COOH}$ $m_{1}=150,85324 \mathrm{~g}$

Foi feita a verificação para constatar se havia reagente em excesso, cujo cálculo segue:

$1 \mathrm{~mol} \mathrm{Cu}\left(\mathrm{CH}_{3} \mathrm{COO}\right)_{2}$ $2 \mathrm{~mol} \mathrm{NH}_{2} \mathrm{CH}_{2} \mathrm{COOH}$

$181,62982 \mathrm{~g}$ $150,85324 \mathrm{~g}$

$2,0036 \mathrm{~g}$ $\mathrm{m}_{2}=1,6640965215 \mathrm{~g} \mathrm{NH}_{2} \mathrm{CH}_{2} \mathrm{COOH}$

$181,62982 \mathrm{~g}$ $150,85324 \mathrm{~g}$

$\mathrm{m}_{3}$ $1,5009 \mathrm{~g} \mathrm{~m}_{3}=1,8071086629 \mathrm{~g} \mathrm{Cu}\left(\mathrm{CH}_{3} \mathrm{COO}\right)_{2}$

Percebeu-se, através dos cálculos, que o reagente em excesso é o $\mathrm{Cu}\left(\mathrm{CH}_{3} \mathrm{COO}\right)_{2}$, logo partiu-se do reagente limitante, $\mathrm{NH}_{2} \mathrm{CH}_{2} \mathrm{COOH}$, para proceder ao cálculo do rendimento.

$2 \mathrm{~mol} \mathrm{NH}_{2} \mathrm{CH}_{2} \mathrm{COOH}$ $1 \mathrm{~mol}\left[\mathrm{Cu}\left(\mathrm{NH}_{2} \mathrm{CH}_{2} \mathrm{COO}\right)_{2}\right] . \mathrm{H}_{2} \mathrm{O}$ 
$150,85324 \mathrm{~g}$ $229,6745 \mathrm{~g}$

$1,5009 \mathrm{~g}$ $\mathrm{m}_{4}=2,2851246486 \mathrm{~g}$

$2,2851246486 \mathrm{~g}$ $100 \%$

$1,7776 \mathrm{~g}$ $R=77,790067211 \%$

Os cálculos demonstraram que o rendimento da reação foi de aproximadamente $77,8 \%$. Podemos considerar como favoráveis os rendimentos reacionais $>60 \%$.

Há grande interesse entre os profissionais nas estruturas, propriedades e usos dos complexos, segundo Atkins e Jones (2012), em parte porque participam de muitas reações biológicas.

As cores dos compostos de coordenação geralmente são determinadas pelos átomos centrais, embora também possam ser devidas a outros cromóforos (ou pigmentos) que façam parte da sua composição. Os complexos de metais de transição são fascinantes pelas variedades de cores que exibem. Para um determinado metal, esta mudança de coloração também pode ser observada em função do ligante (SOUZA, s.d.).

Os complexos dos metais do grupo $d$ são muitas vezes magnéticos e vivamente coloridos e são usados em química para análise, na dissolução de íons, na eletrodeposição de metais e na catálise. Eles também são objetos de pesquisa na conservação de energia solar, na fixação do nitrogênio atmosférico e novos fármacos (ATKINS e JONES, 2012).

Muitos complexos são importantes para nossas vidas, e a carência deles em nosso organismo podem acarretar sérias doenças. Segundo Brown (2003) elementos como $\mathrm{V}, \mathrm{Cr}, \mathrm{Mn}, \mathrm{Fe}, \mathrm{Co}, \mathrm{Ni}, \mathrm{Cu}, \mathrm{Zn}$, Mo e Cd formam complexos com uma variedade de grupos doadores presentes nos sistemas biológicos, como as enzimas. O glicinato de cobre (II) também é largamente utilizado para suplementação parenteral em animais, sendo fonte de reposição de cobre. 
Há complexos, ainda, que são utilizados em pigmentos de tintas, produção de cores em vidros e pedras preciosas. Exemplos de outros complexos importantes para a manutenção da vida são a hemoglobina, responsável pelo transporte de oxigênio no sangue, cujo átomo central é o $\mathrm{Fe}^{2+}$ e a clorofila, responsável pela fotossíntese, cujo átomo central é o $\mathrm{Mg}^{2+}$.

Há muitos metais que formam complexos indispensáveis a diversas funções biológicas dos seres vivos, contribuindo para a manutenção de necessidades celulares básicas. Esses compostos são capazes de interagir com muitos sítios receptores, o que representa um ganho em potencial na formulação de agentes terapêuticos seletivos.

As atividades exercidas por íons metálicos nos meios biológicos têm estimulado a pesquisa e o desenvolvimento de compostos inorgânicos como agentes terapêuticos. O envolvimento destes compostos na medicina, principalmente aqueles contendo metais de transição, foi muito limitado até 1965, quando houve a clássica demonstração da atividade antitumoral do complexo denominado cisplatina, [PtCl2(NH3)2] (COHEN, 2007 apud GUERRA et al, 2011).

\section{CONCLUSÃO}

A proposta de síntese do composto pretendido foi cumprida com êxito. O uso de estratégias como a experimentação contribui muito para a formação dos alunos, além de poder ser utilizada como marco inicial para a introdução de um conteúdo. Acreditase que erros analíticos e equipamentos sem a devida calibração possam ter contribuído para perda do rendimento reacional. Não se pode determinar apenas qualitativamente qual forma isomérica foi sintetizada ou se há possibilidade de uma mistura racêmica. Para isso seriam necessários métodos analíticos instrumentais mais seletivos, capazes de determinar a estrutura dos compostos. Especulou-se a formação do cis-bis-[Cu(gly $\left.)_{2}\right] . \mathrm{H}_{2} \mathrm{O}$ com base em informações de outros experimentos, dizendo que através da mistura de glicina ao filtrado remanescente seja possível a obtenção da forma trans do complexo de interesse. O estudo de síntese química é relativamente complexo, mas importante para o desenvolvimento de novos produtos 
e princípios ativos de interesse não só no meio acadêmico, mas em diferentes áreas do conhecimento, como os setores farmacêutico e agroveterinário, por exemplo.

\section{REFERÊNCIAS}

ATKINS, Peter; JONES, Loretta. Princípios de química: questionando a vida moderna e o meio ambiente, $5^{\circ}$ ed. Bookman, 2012, 922 p.

BROWN, Theodore. Química: a ciência central, 9² ed. São Paulo, Pearson, 2003.

Círculo cromático. Disponível em < http://www.elgin.com.br/blog/2017/04/18/coresvoce-sabe-como-combina-las-na-hora-de-decorar/>; 2017. Acesso em 30/10/2018.

COELHO, Augusto Leite. Química Inorgânica, Ceará, Núcleo Gráfico da UECE, 2010, $132 \mathrm{p}$.

COTTON, Simon. Uppingham Scholl, Rutland, UK Molecule od the Month April, 2010.

Disponível em <http://www.chm.bris.ac.uk/motm/glycine/Glycine\%20\%20Molecule\%20of\%20the\%20Month\%20-\%20April\%202010.pdf>. Acesso em $30 / 10 / 2018$.

GUERRA, Wendell; et al. Coordenação de metais a antibióticos como uma estratégia de combate à resistência bacteriana. Revista Química Nova, 34(1); 2011: 111-118.

HOEHNE, Lucélia; DALL'OGLIO, Camila. Compostos de coordenação e a química orgânica. Revista Destaques Acadêmicos, 5(4); 2013: 79-83.

ISENMANN, Armin Franz. Princípios da Síntese Orgânica. 2ª ed. Timóteo, 2013.

OLIVEIRA, Leandro José Dias Gonçalves de.; et al. Rotas de síntese do antibiótico Linezolida e correlação entre sua estrutura química e bioatividade. Revista Eletrônica Acervo em Saúde, Vol. Sup. 13, 2018; p. 1557-1566.

RUSSEL, John. Química Geral, 2ª ed. Pearson, 1994, vol.1, 662 p. 
SHRIVER, Duward; ATKINS, Peter. Química Inorgânica, 3a ed. Bookman, 2003, 816 p.

SOUZA, Anne. Compostos de coordenação: cor e propriedades magnéticas, s.d.; p. 152-160.

Enviado: Julho, 2019.

Aprovado: Julho, 2019. 